\title{
Experiência docente com literatura no ensino fundamental
}

\author{
Leandro Bernardo Guimarães*
}

\begin{abstract}
Resumo
Com o intuito de refletir sobre práticas e estratégias de ensino que possam fomentar e promover a leitura literária, este artigo objetiva compartilhar experiências vivenciadas em uma turma de oitavo ano do ensino fundamental do Centro de Ensino e Pesquisa Aplicada à Educação (Cepae/UFG), como atividade do Estágio IV de Língua Portuguesa da Faculdade de Letras/UFG. Nosso objetivo é pensar náo só nos problemas que rondam a presença da literatura na escola, mas também em possíveis soluções e estratégias didático-pedagógicas que aproximem o aluno do texto literário. Neste sentido, propomos, por meio de uma experiência com contos em sala de aula, pensar, ancorados também em trabalhos críticos e teóricos, em métodos e modos de se trabalhar a leitura literária com alunos do ensino fundamental.
\end{abstract}

Palavras-chave: ensino, leitura, literatura, humanização.

Teaching experience with literature at elementary school level

\begin{abstract}
In order to reflect on teaching practices and strategies which could foster and promote the reading or literature, this article presents experiences lived out in an eighth grade class at elementary school in the Center for Teaching and Applied Research in Education (Cepael UFG), as an activity of the $4^{\text {th }}$ teaching experience in Portuguese Language module at the Faculty of Arts/UFG. Our goal is not just to think about the problems that plague the teaching of literature in schools, but also to think of possible solutions and didactic teaching strategies which encourage students to read literary texts. In this regard, by means of an experiment with short stories in the classroom, we propose to think out methods and ways of working on the reading of literature, well-grounded in critical and theoretical work, with elementary school students.
\end{abstract}

Keywords: teaching, reading, literature, humanization.

\section{Introduçáo}

Na parte inicial deste artigo abordaremos o lugar que a literatura ocupa na escola atualmente. Em seguida, falaremos de problemas recorrentes que

\footnotetext{
* Graduando do curso de Licenciatura em Letras na UFG. E-mail: leandro.bguimaraes@hotmail.com
} 
dificultam o seu trabalho e abordagem na educação básica, em especial no ensino fundamental. Posteriormente, relataremos nossa experiência prática realizada em uma turma de oitavo ano do ensino fundamental do Centro de Ensino e Pesquisa Aplicada à Educação (Cepae/UFG), como atividade do Estágio IV de Língua Portuguesa da Faculdade de Letras/UFG. Por fim, refletiremos sobre as possíveis soluçôes e alternativas para um trabalho satisfatório com a leitura literária na escola.

A discussáo que propomos leva a observar que a mediação adequada do professor no processo de leitura literária possibilita e valida o trabalho em sala de aula com textos tidos como inacessíveis a alunos do ensino fundamental. Por exemplo, as peculiaridades e sutilezas típicas da escrita machadiana, como o humor fino e irônico, podem ser sentidas pelos alunos, causando-lhes prazer estético, se o docente colocar em cena o texto e por meio dele ir provocando a inferência de sentidos, significaçôes, possibilidades de leitura. Conforme percebemos na vivência do estágio prático, a escola tem que criar situaçóes que envolvam o aluno com a leitura da literatura como atividade lúdica de construção e reconstrução de sentidos.

Isso não é possível se, ao invés da leitura do texto integral, se privilegie o trabalho com o livro didático com suas listas de características estilísticas, informaçóes históricas e biográficas acerca de determinado escritor ou movimento literário. Neste sentido, propomos, por meio de uma experiência em sala de aula, pensar, ancorados também em trabalhos críticos e teóricos, em métodos e modos de trabalhar a leitura literária com alunos do ensino fundamental.

\section{O lugar que a literatura ocupa na escola e na sociedade}

Antes de qualquer problematizaçáo sobre o ensino de literatura na educação básica, faz-se necessário responder ou tentar responder a seguinte questão, nada nova, recorrente nos cursos de letras e em outras esferas: qual a importância da literatura?

É sabido que a música, o teatro, a dança, a pintura, a escultura, a poesia acompanham a humanidade desde tempos remotos. Ao homem a arte se apresenta como uma possibilidade de transcendência do real corriqueiro e das limitaçóes da existência, permitindo-lhe experienciar, seja em seu fazer artístico seja na apreciação e fruição estética de determinada obra artística, o poder da criação e recriação do mundo. 
Nesse sentido, Ernst Fischer, em $A$ necessidade da arte, observa que "a arte é necessária para que o homem se torne capaz de conhecer e mudar o mundo. Mas a arte também é necessária em virtude da magia que lhe é inerente" (FISCHER, 1983, p. 15). Entre todas as manifestações artísticas, a literatura figura como uma das mais importantes e encantatórias, pois sua materialidade é a linguagem, elemento constitutivo do humano, e por meio dela temos acesso a mundos possíveis; conforme afirma Aristóteles em sua Poética, o poeta náo canta o que aconteceu como faz o historiador, mas o que poderia acontecer, ou seja, a literatura é o caminho para mundos possíveis.

Por sua vez, Antonio Candido (1995, p. 249) entende a literatura como algo de fundamental importância para a formação e humanização do homem, na medida em que desenvolve e confirma no indivíduo traços que o tornam mais aberto e compreensivo para com a natureza, a sociedade e o semelhante.

Na mesma linha de raciocínio de Candido, Mario Vargas Llosa (2010, p. 3), no texto "Em defesa do romance", afirma o seguinte em relação à pertinência da literatura em nossa sociedade:

A literatura, ao contrário, diferentemente da ciência e da técnica, é, foi e continuará sendo, enquanto existir, um desses denominadores comuns da experiência humana, graças ao qual os seres vivos se reconhecem e dialogam, independentemente de quâo distintas sejam suas ocupaçôes e seus desígnios vitais, as geografias, as circunstâncias em que se encontram e as conjunturas históricas que lhes determinam os horizontes.

Roland Barthes, em aula inaugural da cadeira de Semiologia Literária do Colégio de França, pronunciada em 1977, afirma que, se porventura todas as disciplinas do currículo fossem eliminadas, "a disciplina literária [...] devia ser salva, pois todas as ciências estão presentes no monumento literário" (BARTHES, 2007, p. 17).

A essas vozes em defesa da literatura se somam muitas outras como as de Umberto Eco, Italo Calvino, Todorov. Inclusive, vale citar este último, quando, em $A$ literatura em perigo, afirma que a literatura "longe de ser um simples entretenimento, uma distração reservada às pessoas educadas, ela permite que cada um responda melhor à sua vocaçáo de ser humano" (TODOROV, 2009, p. 24).

Ora, dada a importância da literatura para a formação crítica, intelectual, social, humanitária do homem, o natural seria que ela estivesse pre- 
sente em lugar de destaque na sociedade e principalmente na escola. Mas isso não acontece. Estatísticas e estudos apontam, a cada nova pesquisa, números que expressam o crescente desinteresse pela leitura, principalmente pela leitura literária. Quando se lê, privilegiam-se textos cuja funçáo pragmática de informar e instruir condiz com um mundo em que a supremacia da agilidade, da interatividade e a busca pelo instantâneo e imediato aumentam paralelamente à crescente busca do homem por empregabilidade e sucesso em um mercado de trabalho cada vez mais seletivo e excludente. Desse modo, há uma preferência maior pela leitura de jornais, revistas, livros teóricos ou técnicos de determinada área do conhecimento, ficando a leitura literária excluída do cotidiano das pessoas.

Perante esta realidade, como têm se posicionado a escola e o professor para formarem alunos leitores de literatura? Presente tanto no ensino fundamental, quanto no ensino médio, a literatura é um produto cultural escolarizado. Natural seria que os discentes concluintes da educação básica saíssem com boa formação literária e adeptos da leitura, de modo a continuar lendo e usufruindo do prazer estético da leitura literária.

No entanto, uma série de problemas e equívocos tem impossibilitado um trabalho satisfatório com a literatura. Problemas como seleção inadequada de obras literárias, o uso excessivo do livro didático e de fragmentos de textos como recursos para análises gramaticais, enfoque excessivo na historiografia e em elementos extrínsecos à obra apresentam-se como entrave e contribuem para a falta de motivaçáo para a leitura literária, causando no discente rejeição, em vez de compreensão e fruiçấo das qualidades da literatura.

\section{Problemas recorrentes no ensino de literatura na educaçáo básica}

A arte, desde tempos remotos, se apresenta como uma possibilidade de transcender as limitaçôes da existência. No caso da arte literária, o contato com a representação de outras realidades e a problematização de situaçóes e conflitos eminentemente humanos, possibilita ao leitor refletir sobre seus problemas. Segundo Vera Tietzmann (2009, p. 72), a literatura

favorece o aguçamento da percepção, o ativamento da memória, o cotejo entre realidade e ficção, a análise avaliativa, o julgamento crítico. Em outras palavras, ela contribui para tornar o leitor mentalmente mais ativo diante do texto e, por extensão, diante da vida. Na leitura de ficção, principalmente, o exercício que o leitor é levado constantemente 
a fazer de vivenciar emoçóes alheias, de compartilhar angústias e dilemas com os personagens das narrativas é, de fato, um exercício de cidadania. Saindo do apertado círculo de seu mundo pessoal e sendo capaz de sentir com o outro (mesmo que se trate de um outro inventado), o leitor tornase mais apto a criticar, a julgar, a exigir, a definir-se como verdadeiro cidadão.

Desse modo, o aluno não pode ser privado do contato com a literatura. Um mundo de sonhos, fantasias, criatividade, dramas, angústia, alegrias, felicidade, tristeza, ou seja, realidades ficcionais e poéticas embebidas de humanismo. Mas porque em geral quando se fala em literatura os alunos "torcem o nariz"?

O escritor francês Daniel Pennac, em seu livro Como um romance, chama atenção para o fato de que os pais, quando seus filhos eram crianças e ainda não estavam matriculados na escola, tinham o hábito de lhes contar histórias, contos de fadas, lendas, parlendas antes de dormirem, o que constituía um prazer imenso para as crianças, a ponto de desejarem ouvir repetidas vezes as peripécias de Chapeuzinho Vermelho, a Branca de Neve e os sete anóes, e muito mais. Sobre essa fase afirma Pennac (1992, p. 19):

Resumindo, ensinamos tudo do livro a ele, naquele tempo em que ele não sabia ler. [...] As histórias que líamos para ele formigavam de irmãos, de pais, de duplos ideais, esquadrilhas de anjos da guarda, legióes de amigos tutelares encarregados de suas tristezas, mas que, lutando contra seus próprios ogres, encontravam, eles também, refúgio nas batidas de seu coração. Ele tinha se tornado o anjo recíproco deles: um leitor. Sem ele, o mundo deles não existiria. Sem eles, descobriu a virtude paradoxal da leitura que é nos abstrair do mundo para lhe emprestar um sentido.

Com o tempo, quando a criança inicia sua vida escolar, a tendência é os pais deixarem de ler e contar para os filhos as chamadas historinhas, se eximindo do incentivo à leitura por entender que esta é tarefa da escola. E na escola, aquilo que outrora era motivo de satisfação e prazer para a criança e o adolescente, se torna pouco a pouco um tormento, e a literatura passa a ser sinônimo de coisa chata, de fichas de leitura, avaliação, características estilísticas e históricas de determinado movimento literário. Dissocia-se leitura literária do prazer. Grande responsável por tal dissociação é a própria escola.

No ensino fundamental, conforme Rildo Cosson (2011, p. 21), “a literatura tem um sentido táo amplo que engloba qualquer texto escrito 
que apresente parentesco com ficção ou poesia”. Nesta fase do ensino, não há propriamente dito um estudo sistemático e periodizado da história da literatura brasileira e partes da portuguesa, ficando esse contceúdo a cargo do ensino médio. Há, por outro lado, em razão dessa aparente liberdade na utilização da literatura no ensino fundamental, a recorrência de alguns equívocos, como, por exemplo, em relação à escolha do texto literário, guiada pela temática e linguagem compatíveis com a idade dos alunos. Isso significa, na maioria das vezes, deixar de lado textos reconhecidamente de qualidade estética, a chamada literatura adulta, para se trabalhar textos de literatura infantojuvenil, às vezes problemáticos e pobres, mas cujo enredo e linguagem acessíveis vão ao encontro do pensamento errôneo de que por ser criança ou adolescente o aluno náo estaria preparado para usufruir e se deleitar com textos mais complexos. E esse problema se liga a outro: a utilização de fragmentos em detrimento de textos integrais.

Essa prática torna o trabalho com literatura incompleto, pois, além de reduzir a obra e possivelmente comprometer seu entendimento e fruição por parte dos alunos, com frequência serve de subsídio para análises gramaticais.

Esse problema, que está associado a um dos principais entraves à formação de leitores, tanto no ensino fundamental quanto no médio, pode ser verificado tanto em colégios públicos quanto em particulares. Referese à utilização constante do livro didático como ferramenta quase que exclusiva para se trabalhar literatura. Élder Pinheiro (2006, p. 103) observa, em artigo intitulado "Reflexôes sobre o livro didático de literatura", que o uso irrefletido e excessivo do livro didático torna-se um obstáculo para atividades e práticas mais proveitosas. Segundo ele, levar para a "sala de aula antologias de poemas, de contos e crônicas e discuti-las, encená-las suscita um tipo de vibraçáo, de alegria bem mais significativa do que ficar listando características de estilos e época”. O contrário tem sido o mais praticado pelo professor, que, por uma série de motivos - dos quais talvez a jornada de trabalho excessiva, com muitas turmas em turnos diferentes, seja o mais significativo -, prefere a praticidade do livro didático à empreita de buscar textos, fazer coletânea de poemas, contos, crônicas. Isso impossibilita ao aluno um contato mais diversificado com a produção literária brasileira, na medida em que há pouca variação de um livro didático para outro quanto aos textos e escritores abordados.

A isso, soma-se o fato de se dar privilégio, quando se trabalha com textos literários, seja no ensino fundamental seja no médio, a elementos 
extrínsecos à obra, como contexto histórico e social, biografia do escritor, deixando para segundo plano ou ignorando os seus elementos intrínsecos. Assim, ao invés de propiciar um contato direto com a obra e, por meio do que ela suscita, estabelecer relaçôes com outros conhecimentos e saberes, há por parte do professor um apego muito grande à história da literatura e a características estilísticas.

Neste ponto, é fundamental distinguirmos leitura da literatura e ensino da literatura. A este respeito, Ivanda Martins, em seu texto "A literatura no ensino médio: quais os desafios do professor?", afirma o seguinte, citando outros estudiosos da área:

Segundo Beach \& Marshall (1991, p. 38), a leitura da literatura está relacionada à compreensão do texto, à experiência literária vivenciada pelo leitor no ato da leitura, ao passo que o ensino da literatura configurase como o estudo da obra literária, tendo em vista a sua organização estética. [...] A escola parece dissociar esses dois níveis, desvinculando o prazer de ler o texto literário (produzido pela leitura da literatura) do reconhecimento das singularidades estéticas da obra (proporcionado pelo estudol ensino da literatura). (MARTINS, 2009, p.. ???)

E essa dissociação entre leitura da literatura e ensino da literatura tem distanciado cada vez mais o aluno da literatura. Hélder Pinheiro (2006, p. 113) comenta que os teóricos, críticos, historiadores e professores de literatura estariam deixando de lado o texto em si, e a possibilidade de, a partir dele, ensaiar uma teoria, para se dedicar à aplicaçáo de conceitos teóricos consagrados. Hélder propóe o abandono dos tradicionais esquemas dos livros didáticos de literatura que sempre iniciam oferecendo conceitos e quase nunca colaboram para formar leitores de literatura. Sua proposta é simples: professores e alunos dedicarem-se à leitura das obras.

\section{Experiências em uma turma do ensino fundamental}

Diante dessas e de outras inquietações e reflexões acerca do trabalho com literatura na educação básica, o estágio prático da Licenciatura em Língua Portuguesa da Faculdade de Letras da Universidade Federal de Goiás constitui um momento importante para o licenciando, na medida em que lhe oferece oportunidade de atuar ativamente em sala de aula, propondo e executando sequências didático-pedagógicas que visam a uma junção entre teoria e prática. Desse modo, realizou-se no Centro de Ensino e Pesquisa 
Aplicada à Educação (Cepae), instituição vinculada à Universidade Federal de Goiás, o estágio prático IV da Licenciatura em Português.

Atuei em uma turma do oitavo ano do ensino fundamental, juntamente com mais dois colegas da graduação. Tendo em vista o cumprimento do plano do curso da série em questão, nos prendemos ao trabalho com as obras literárias já previamente selecionadas pela professora. Um dos eixos norteadores da seleção feita por ela foi a recorrência da temática amorosa, presente tanto em Romeu e Julieta, de Shakespeare, Histórias de amor, da Série Para Gostar de ler, volume 22, e a coletânea de poemas de Carlos Drummond de Andrade, intitulada Declaração de amor: canção de namorados, organizada por Augusto Grańa Drummond e Luis Mauricio Graña Drummond.

Coube a mim o trabalho com o livro de contos Histórias de amor, da Série Para Gostar de ler. Esta coletânea apresenta um total de onze contos de diversos escritores brasileiros e alguns estrangeiros. Há nomes como Lygia Fagundes Telles, Marques Rebelo, Marina Colasanti, Machado de Assis, João do Rio, entre outros ficcionistas representativos. O ponto em comum presente nesses contos é a temática do amor, como o próprio título do livro sugere. No entanto, as visóes de amor veiculadas nos contos são diferentes. O interessante desta seleta de contos é a diversidade, a mescla de autores clássicos e contemporâneos. Essa diversidade de textos é importante, conforme Rildo Cosson (2011, p. 35):

Ao selecionar um texto, o professor náo deve desprezar o cânone, pois é nele que encontrará a herança cultural de sua comunidade. Também não pode se apoiar apenas na contemporaneidade dos textos, mas sim em sua atualidade. Do mesmo modo, precisa aplicar o principio da diversidade entendido, para além da simples diferença entre os textos, como a busca da discrepância entre o conhecido e o desconhecido, o simples e o complexo, em um processo de leitura que se faz por meio da verticalizaçáo de textos e procedimentos. É assim que tem lugar na escola o novo e o velho, o trivial e o estético, o simples e o complexo e toda a miríade de textos que faz da leitura literária uma atividade de prazer e conhecimentos singulares.

O objetivo dos professores da subárea de Língua Portuguesa do Cepae, ao escolherem para trabalhar no oitavo ano do ensino médio obras literárias que tratassem do amor, foi tornar a leitura literária mais atrativa ao abordar um tema que começa a interessar aos alunos, na medida em que estão em fase de transição da infância para a adolescência. 
Com o livro em mãos, a nós, estagiários, surgiram algumas dúvidas: como trabalhá-lo de modo a promover a leitura literária junto aos alunos e sem cair em práticas e metodologias ineficientes que afastam os alunos da literatura e não exploram adequadamente as especificidades da arte literária?

Há vários modos de trabalhar com narrativas de ficção em sala de aula. O primeiro passo foi escolher, dentre os onze contos da coletânea, qual seria trabalhado primeiro. Em geral, a tendência, por tratar-se de uma turma do oitavo ano, seria a escolha se dar em razão da facilidade ou simplicidade do enredo e da linguagem do texto. É comum textos mais densos e complexos ficarem de fora ou só aparecerem no ensino médio. Mas tal atitude não seria privar o aluno do contato com uma literatura mais bem elaborada?

Nesse sentido, escolhi começar pelo conto "Fernando e Fernanda", de Machado de Assis, não por tratar-se de um escritor canônico nem por achar que somente o clássico deve ser trabalhado na escola, mas por crer que, se bem mediado, pode haver uma boa recepção por parte dos alunos de textos tidos como difíceis. Além disso, a leitura desse conto, com elementos estilísticos tipicamente machadianos, pode desencadear o interesse pela leitura de outros contos e romances desse grande ficcionista brasileiro. Fora isso, por meio da ficção, os alunos podem refletir sobre o sentimento amoroso visto por outro ângulo, como o faz Machado. A propósito da pertinência da leitura de clássicos por jovens e crianças, Italo Calvino (2007, p. 10) afirma:

as leituras da juventude podem ser pouco profícuas pela impaciência, distração, inexperiência das instruçôes para o uso, inexperiência da vida. Podem ser (talvez ao mesmo tempo) formativas no sentido de que dão uma forma às experiências futuras, fornecendo modelos, recipientes, termos de comparação, esquemas de classificação, escalas de valores, paradigmas de beleza: todas, coisas que continuam a valer mesmo que nos recordemos pouco ou nada do livro lido na juventude.

Escolhido o conto para se trabalhar com a turma, pensei em fazer algo simples, mas muitas vezes tido como perda de tempo pelos professores: ler o conto integralmente com os alunos em sala de aula. Creio na pertinência de se colocar, sempre que possível, o texto literário em cena na sala de aula. O conto foi lido por mim em voz alta, de modo pausado e com ênfase em algumas passagens, enquanto eles acompanhavam com seus respectivos textos. Após a leitura pedi que fizessem comentários a respeito do que entenderam, em termos do enredo, e se haviam alguma palavra ou expressão que lhes eram estranhas, na medida em que o texto é do século XIX. 
Angela Kleiman (2010, p. 23) chama atenção para algumas concepçóes de leitura existentes. Há a leitura como instrumento de decodificação, improdutiva e empobrecedora, pois em nada "modifica a visão de mundo do aluno". Existe a concepção da leitura como avaliação, sendo utilizada com frequência nas primeiras séries. Essa prática, realizada em voz alta, caracteriza-se pela preocupação em aferir a capacidade de leitura do aluno, verificar se ele conhece as letras, as pronúncias etc. Há também, segundo Kleiman (2010, p. 26), a união desses aspectos e concepçóes errôneas em uma concepção autoritária de leitura, segundo a qual "a contribuição do aluno e sua experiência é dispensável, e a leitura torna-se uma avaliação do grau de proximidade ou de distância entre a leitura do aluno e a interpretação 'autorizada”.

Na semana posterior à leitura do conto "Fernanda e Fernando", com o objetivo de verificar por escrito a compreensão dos sentidos do texto por parte dos alunos, elaborei uma atividade contendo quatro questóes discursivas. Não que ao fim de cada leitura literária o professor tenha que aplicar fichas de leitura, questionários, avaliação ou prova. A presença da literatura em sala de aula náo pode ser julgada satisfatória unicamente se estiver atrelada a exercícios ou a atividades avaliativas. No entanto, o docente pode se valer de mecanismos para diagnosticar o desempenho de seus alunos e o seu próprio, enquanto professor. Para Rildo Cosson (2011, p. 113),

é a leitura literária feita pelo aluno que está no centro do processo de ensino e aprendizagem, devendo a avaliação buscar registrar seus avanços para ampliá-los e suas dificuldades para superá-las. $\mathrm{O}$ professor não deve procurar pelas respostas certas, mas sim pela interpretação a que o aluno chegou, como ele pensou aquilo. O objetivo maior da avaliaçáo é engajar o estudante na leitura literária e dividir esse engajamento com o professor e os colegas - a comunidade de leitores.

A primeira versão das questóes que elaborei, talvez por falta de experiência na docência ou por equívoco, não contribuía em nada para engajar os alunos na leitura literária. Essas questóes estavam mais no âmbito da verificação de leitura e não possibilitavam ao aluno exercitar sua reflexão acerca do conto, mas apenas pediam para que ele identificasse fatos pontuais. Orientado pela professora da turma, percebi que havia caído no equívoco das famigeradas fichas de leitura. Praticamente refiz as questóes, procurando de fato elaborar perguntas que provocassem os discentes e contribuíssem para o entendimento do conto de Machado de Assis. 
As questôes refeitas procuraram chamar a atenção do aluno para algumas peculiaridades do conto "Fernando e Fernanda", principalmente no que se refere à visão de amor veiculada pelo narrador e a ironia em relação ao comportamento das personagens. Como anteriormente essa turma do oitavo ano havia lido a peça Romeu e Julieta, de Shakespeare, casal ícone do amor de todos os tempos, foi interessante que vissem esse conto de Machado de Assis, que ridiculariza a idéia de amor eterno.

A resolução desta atividade foi feita em sala, utilizando-se duas aulas. $\mathrm{Li}$ os enunciados e expliquei com clareza o que se pedia. Durante o tempo em que eles respondiam os exercícios, contaram com o meu auxílio, o dos outros dois estagiários e o da professora da turma. Ao fim da aula todos os trinta alunos entregaram a atividade resolvida.

A correção das resoluçóes mostrou que de modo geral conseguiram apreender bem os sentidos do conto. $\mathrm{Na}$ questáo três, que pergunta sobre que visão teria acerca do destino o narrador machadiano, alguns alunos não perceberam a ironia e acharam que o narrador acreditava que o destino era o principal responsável pelas açóes. Como exemplo, cito essa resposta:

"O narrador machadiano acredita no destino, pois no conto ele fala que tudo que aconteceu com o Fernando e a Fernanda é culpa do destino, sendo acontecimentos bons ou ruins".

No entanto, o narrador ironiza e não crê no destino governando o comportamento dos personagens. A maioria das respostas deu mostras de que entenderam e perceberam as sutilezas do narrador e da linguagem machadiana, como esta:

"Machado de Assis tinha uma visão irônica acerca do destino, ele pensava que o destino não é algo pronto e acabado, ou seja, nós construímos nosso próprio destino a partir das nossas escolhas".

Dando sequência ao trabalho com o livro de contos, optei em dividir a turma de trinta alunos em dez trios, de modo que cinco contos fossem trabalhos. Assim, cada um destes cinco contos foi trabalhado duas vezes, ou seja, por dois trios. Sáo estes os contos e seus respectivos autores: "Stela me abriu a porta", de Marques Rebelo; "Mamon e o arqueiro", do escritor estadunidense O. Henry; "Uma surpresa para Daphne", de Luís Fernando Veríssimo; "A parada da ilusão", de João do Rio; e "Os amantes", de Orlando Bastos. 
Como se percebe, a diversidade marca essa escolha, propiciando ao aluno o contato com diferentes representaçóes ficcionais que abordam o amor, sentimento universal que tem perpassado a literatura e a arte ao longo dos séculos, sob olhares e perspectivas distintas.

Destinei duas aulas para que os grupos reunidos fizessem a leitura em silêncio dos contos selecionados e a partir da leitura pensassem e sistematizassem por escrito, em um pequeno roteiro, como apresentariam seus respectivos contos aos colegas. Meu objetivo ao propor tal atividade foi colocá-los frente a frente com o texto literário, não como agentes passivos, mas como sujeitos capazes de extrair e propor significados diante do objeto literário. Neste sentido, a fim também de trabalhar com a oralidade, propus que apresentassem suas propostas, seja por meio de seminário, teatro, curta-metragem etc. Ou seja, tiveram liberdade para exporem, desde que se trabalhasse o conto.

Tiveram aproximadamente quinze dias para se organizar. Cada grupo teve em média quinze minutos para a apresentaçáo. Houve trabalhos muito bons, criativos, que exploraram o conto fazendo diálogo inclusive com outras linguagens, como imagens, vídeos. Por outro lado, em se tratando de uma turma heterogênea, houve apresentaçôes não satisfatórias, nitidamente mal planejadas, demonstrando falta de habilidade e de interesse. No entanto, creio que esse trabalho foi proveitoso e pode ser feito mais vezes, na media em que é importante que o aluno exercite a oralidade e se acostume com práticas expositivas. Além disso, atividades como essa podem aproximar o estudante da leitura literária, principal responsabilidade e desafio do professor de Língua Portuguesa.

\section{Consideraçóes finais}

Conforme percebemos na vivência do estágio prático, a escola tem que criar situaçóes que envolvam o aluno com a leitura da literatura como atividade lúdica de construção e reconstrução de sentidos. Isso não é possível se ao invés da leitura do texto integral, o professor privilegiar o trabalho com o livro didático, com suas listas de características estilísticas, informaçôes históricas e biográficas acerca de determinado escritor ou movimento literário. Vimos também que, contrariando a percepção de que escritores clássicos ou da chamada literatura adulta são de difícil acesso e entendimento para alunos do ensino fundamental, que não estariam aptos a usufruírem 
de um texto mais complexo e rico de sentidos, o trabalho com o conto "Fernando e Fernanda", de Machado de Assis, bem como com os outros contos do livro Histórias de amor, da Série para Gostar de ler, demonstrou que há receptividade e possibilidade de fruição por parte dos alunos.

Encerramos esse artigo ciente de que há, sim, lugar para a literatura na escola e na sociedade. É o que exemplarmente afirma Marisa Lajolo (2000, p. 106):

É à literatura, como linguagem e como instituiçáo, que se confiam os diferentes imaginários, as diferentes sensibilidades, valores e comportamentos através dos quais uma sociedade expressa e discute, simbolicamente, seus impasses, seus desejos, suas utopias. Por isso a literatura é importante no currículo escolar: o cidadão, para exercer plenamente sua cidadania, precisa apossar-se da linguagem literária, alfabetizar-se nela, tornar-se seu usuário competente, mesmo que nunca vá escrever um livro: mas porque precisa ler muitos.

\section{Referências}

BARTHES, R. Aula. Tradução de Leyla Perrone-Moisés. São Paulo: Cultrix, 2007.

CALVINO, I. Porque ler os clássicos. In: Porque ler os clássicos. Tradução de Nilson Moulin. São Paulo: Cia das Letras, 1993.

CANDIDO, A. O direito à literatura. In: . Vários escritos. 3. ed. ampl. São Paulo: Duas Cidades, 1995.

COSSON, R. Letramento literário: teoria e prática. São Paulo: Contexto, 2011.

FISCHER, E. A função da arte. In: . A necessidade da arte. Tradução de Leandro Konder. Rio de Janeiro: Jorge Zahar, 1983.

KLEIMAN, A. Oficina de leitura: teoria \& prática. Campinas, SP: Pontes Editores, 2010.

LAJOLO, M. Do mundo da leitura para a leitura do mundo. 6. ed. Sáo Paulo: Ática, 2000.

LLOSA, M. V. Em defesa do romance. Piauí, São Paulo, n. 37, out. 2009. Disponível em: <http.//www.revistapiauí.com.br/interna_print. aspx?id=37>. Acesso em: 3 ago. 2010. 
MARTINS, I. A literatura no ensino médio: quais os desafios do professor? In: BUZEN, C.; MENDONÇA, M. (Org.). Português no ensino médio e formação de professor. São Paulo: Parábola Editorial, 2006.

PAES, J. P. Histórias de amor. Vários autores. São Paulo: Ática, 2008. (Série Para Gostar de Ler, v. 22).

PENNAC, D. Como um romance. Tradução de Leny Werneck. Rio de Janeiro: Rocco, 1993.

PINHEIRO, H. Teoria da literatura, crítica literária e ensino. In:

PINHEIRO, H.; NÓBREGA, M. (Org.). Literatura: da crítica à sala de aula. 3. ed. Campina Grande: Bagagem, 2002.

PINHEIRO, H. Reflexões sobre o livro didático de literatura. In: BUZEN, C.; MENDONÇA, M. (Org.). Português no ensino médio e formação de professor. São Paulo: Parábola Editorial, 2006.

SILVA, V. M. T. Leitura literária \& outras leituras: impasses e alternativas no trabalho do professor. Belo Horizonte: RHJ, 2009.

TODOROV, T. A literatura em perigo. Tradução de Caio Meira. Rio de Janeiro: Difel, 2009.

Recebido em: 25 abr. 2012

Aceito em: 10 jun. 2012 